\title{
ORIGENES DE LA ASOCIACION MADRES DE PLAZA DE MAYO DE MAR DEL PLATA (1976-1986)
}

\section{PAULA ZUBILLAGA (UNLP)}

Universidad Nacional de La Plata

paulazubillaga@gmail.com

\section{Resumen:}

La represión desplegada por las fuerzas policiales, las Fuerzas Armadas y la Concentración Nacional Universitaria en Mar del Plata, Argentina, durante la última dictadura, llevó a la conformación de grupos de oposición, denuncia y resistencia a la misma. Así, la Asociación Madres de Plaza de Mayo de Mar del Plata nació en 1984 fruto de las distintas divisiones que se produjeron en la primera organización de derechos humanos de la ciudad, la Comisión Madres, Abuelas y Familiares de Detenidos Desaparecidos, conformada entre 1976 y 1977 y cuyo accionar se extendió hasta mediados de los años '80. En este trabajo intentaremos indagar la experiencia de dicha Comisión -de la cual participaron mujeres que luego integrarían la Asociación- y el surgimiento de la organización de Madres local. Por tal motivo, el recorte temporal elegido va desde el golpe de estado de 1976 a 1986, año en que se produce la fractura de Madres de Plaza de Mayo, en la cual la filial marplatense queda bajo la órbita de la Asociación liderada a nivel nacional por Hebe de Bonafini.

\section{Palabras claves:}

Movimiento de derechos humanos - Asociación Madres de Plaza de Mayo - Mar del Plata

\begin{abstract}
:
The repression deployed by the police, the Military Forces and the National University Concentration in Mar del Plata, Argentine, during the last dictatorship, led to the formation of opposition groups, denunciation and resistance to it. Thereby, the Mothers of Plaza de Mayo of Mar del Plata was born in 1984 due to the divisions that occurred in the first human rights organization in the city, the "Mothers, Grandmothers and Relatives of the Disappeared Committee", established between 1976 and 1977 and whose actions lasted until the mid-80s.

This paper attempts to investigate the experience of this Committee - which included women who then integrated the Association- and the emergence of the local Mothers organization. Therefore, the temporary stage chosen goes from the putsch of 1976-1986, when the rupture of Mothers of Plaza de Mayo occurs, thereafter the Mar del Plata's subsidiary will be under the aegis of the Association led nationwide by Hebe de Bonafini.
\end{abstract}

\section{Keywords:}

Human Rights Movement - Association Mothers of the Plaza de Mayo - Mar del Plata 


\title{
ORIGENES DE LA ASOCIACION MADRES DE PLAZA DE MAYO DE MAR DEL PLATA (1976-1986)
}

\author{
PAULA ZUBILLAGA (UNLP) \\ paulazubillaga@gmail.com
}

\section{La Comisión Madres, Abuelas y Familiares de Detenidos Desaparecidos}

Tras el golpe de Estado de 1976 la ciudad de Mar del Plata fue ocupada militarmente por las tres Fuerzas Armadas ${ }^{1}$, quedando dentro de la Zona I -dependiente de la jurisdicción del Primer Cuerpo del Ejército-, Subzona 15 -cuyo jefe era el coronel Alberto Pedro Barba-, Área 1512.

El intendente Luis Nuncio Fabrizio, miembro del Partido Socialista Democrático ${ }^{3}$, fue reemplazado por un hombre de la Marina, el Capitán de Navío Emilio Menozzi, medida apoyada por las fuerzas conservadoras locales, las cuales habían dado su apoyo también a los golpes de 1955 y 1966. No obstante, Fabrizio volvió como intendente luego de la Guerra de Malvinas, conduciendo la transición a la democracia en la ciudad de Mar del Plata. De esta forma, el socialismo marplatense, que desde 1958 había ganado todas las elecciones, cerró su ciclo de intendencias como brazo político de la última dictadura ${ }^{4}$. Luego, en las elecciones de 1983, fue elegido intendente el radical Ángel Roig, superando por primera vez a socialistas y peronistas ${ }^{5}$, mientras que la gobernación de la provincia de Buenos Aires también sería obtenida ese año y hasta 1987 por un radical, Alejandro Armendáriz.

Ciertamente, las detenciones ilegales y las torturas a militantes políticos de la ciudad se iniciaron antes de $1976^{6}$, como quedó demostrado en los testimonios del Juicio por la Verdad de Mar del

\footnotetext{
1 Cabe destacar que Mar del Plata es una de las pocas ciudades de la Argentina donde se encuentran simultáneamente bases militares de las tres Fuerzas: Ejército, Marina y Aeronáutica.

${ }^{2}$ El área incluía al Partido de General Pueyrredón, el Partido de General Lavalle, el Partido de General Madariaga, General Alvarado, Mar Chiquita, Balcarce, Lobería, Necochea y San Cayetano.

${ }^{3}$ El Partido Socialista Democrático había ganado las elecciones de 1973 con 54.530 votos, mientras que la segunda fuerza, el Frente Justicialista de Liberación, obtuvo 50.291 votos. Datos extraídos de Lobato, Mirta Zaida, (Directora) Mar del Plata de la prehistoria a la actualidad. Caras y contracaras de una ciudad imaginada. Facultad de Humanidades. Universidad Nacional de Mar del Plata. 1999.

${ }^{4}$ Otro de los intendentes civiles de Mar del Plata durante la última dictadura fue Mario Roberto Russak (1978-1981) quien, a partir del apoyo del gobierno militar provincial y gracias a las obras dedicadas al turismo -como el complejo Punta Mogotes y la Peatonal San Martín-, se convirtió en el dirigente de las fuerzas conservadoras de la ciudad nucleadas en la Unión Conservadora. En 1981 asumió como intendente de facto por unos meses Carlos Raúl Martín. ${ }^{5}$ Para ampliar estos temas véase entre otros Lobato, Mirta Zaida, Mar del Plata de la prehistoria a la actualidad..., op. cit.; Diario La Capital, 100 años. 1905-2005, Mar del Plata; 25 de mayo de 2005. Para dichas elecciones, militantes del Partido Obrero habían propuesto a una madre de un detenido-desaparecido -integrante luego de Familiares de Detenidos-Desaparecidos-, presentarse como candidata a la intendencia, la cual finalmente no acepto. Conversaciones con Jorge Censi, integrante del Grupo de Apoyo de Madres de Plaza de Mayo Mar del Plata, año 2015.

${ }^{6}$ Dejamos fuera del análisis de este trabajo el contexto político marplatense previo al golpe de estado de 1976 por razones de espacio y por los pequeños objetivos aquí planteados. Puede tenerse un acercamiento al mismo, sobre todo en torno a la violencia política, el accionar de las organizaciones armadas y las tensiones entre la izquierda y la derecha peronista en Mora, Belén, Juicios por la verdad histórica, rituales de la memoria. La reaparición de una trama en Mar del Plata, Tesis de Licenciatura, Universidad de Buenos Aires, 2005; Bozzi, Carlos, Luna Roja. Desaparecidos de las playas marplatenses, Mar del Plata, Ediciones Suárez, 2007; Andreotti Romanin, Enrique, Memorias en conflicto. El movimiento de derechos bumanos y la construcción del Juicio por la Verdad de Mar del Plata, Mar del Plata, EUDEM, 2013.; Capitán, M.
} 
Plata $^{7}$, pero a partir del golpe de Estado se prohibió toda manifestación y acción política y se llevó a cabo, a manos de las fuerzas policiales, de las FFAA y de la Concentración Nacional Universitaria $(\mathrm{CNU})^{8}$, una persecución y represión sistemática sobre las fuerzas políticas de izquierda de la ciudad -la Juventud Peronista, la Juventud Peronista de Bases Universitarias, la Unión de Estudiantes Secundarios, la Juventud Universitaria Peronista, la Juventud Trabajadora Peronista, Peronismo de Base, Partido Socialista de los Trabajadores, Partido Revolucionario de los Trabajadores, Partido Comunista Revolucionario, Partido Comunista Marxista-Leninista y el Ejército Revolucionario del Pueblo-, así como también sobre trabajadores sindicalizados de distintas ramas -como la industria pesquera y la construcción- que no formaban parte de dichas fuerzas políticas o jóvenes que militaban en centros de estudiantes de escuelas de la ciudad. ${ }^{9}$

Como en distintas localidades del país, en Mar del Plata funcionaron centros clandestinos de detención y tortura pertenecientes a delegaciones locales de la Marina, la Fuerza Aérea, el Ejército y la Policía de la Provincia ${ }^{10}$. Este accionar represivo dejó, entre otras consecuencias, alrededor de 220 personas desaparecidas ${ }^{11}$, la apropiación de menores de edad y de niños nacidos en

Belén, "Entre rezos y habeas corpus. Los orígenes de la Comisión Madres, Abuelas y Familiares de Detenidos Desaparecidos Mar del Plata", Sudamérica N², 2013; Lobato, Mirta Zaida, Mar del Plata de la prehistoria a la actualidad..., op. cit.; Ladeuix, Juan, "La mazorca de Perón: Prácticas e ideologías de la derecha peronista. Una aproximación a partir de un estudio de caso. Mar del Plata 1970-1976”, X Jornadas Interescuelas/Departamentos de Historia de la República Argentina, Rosario, 2005.

${ }^{7}$ Véase Mora, Belén, Juicios por la verdad histórica..., op. cit.; Andreotti Romanin, Enrique, Memorias en conflicto..., op. cit.

8 A partir de los testimonios brindados en el marco del Juicio por la Verdad desarrollado en Mar del Plata entre 2001 y 2008 y a partir de algunas investigaciones, se pudo constatar que varios miembros de la CNU formaron parte de las patotas encargadas de secuestrar personas en la ciudad antes y durante la última dictadura. Así, en 2011 un fiscal federal ordenó la detención de 14 miembros de la CNU por la comisión de delito de lesa humanidad en Mar del Plata. Véase Mora, Belén, Juicios por la verdad histórica..., op. cit.; Andreotti Romanin, Enrique, Memorias en conflicto..., op. cit.; Bozzi, Carlos, Luna Roja..., op. cit.; Ladeuix, Juan, “La mazorca de Perón...”, op. cit.

9 Según las estadísticas vertidas en el anexo número 8 del Informe de la delegación Mar del Plata de la CONADEP, realizadas en base a las denuncias recibidas, alrededor del $44 \%$ de los detenidos-desaparecidos tenía una pertenencia política conocida por el familiar denunciante. El cuadro se divide en peronistas, socialistas, comunistas, radicales, intransigentes, PO, ERP y Montoneros. En el anexo número 17 se consigna la militancia de cada uno de los detenidos-desaparecidos denunciados frente a dicha Comisión. Véase Informe Final de la Delegación de Mar del Plata de la Comisión Nacional sobre la Desaparición de Personas, 1984, pp. 21 y 28. También se hace referencia a la militancia de los detenidos-desaparecidos en Comisión de Memoria Portuaria, Trabajadores militantes del puerto desparecidos en Mar del Plata 1975-1983, Mar del Plata, Del Plata, 2011.

${ }_{10}$ Si se toma como fuente el informe de la CONADEP delegación Mar del Plata, se trata de la Escuela de Suboficiales de Infantería de Marina, la Base Naval de la Armada, la Base Aérea Militar, la Comisaría Cuarta, el Cuartel Central de Bomberos y el Destacamento policial de Batán sobre la ruta 88. No obstante, en dicho informe se deja entender que son más: "Existe la presunción cierta de que hay otras dependencias en la zona que sirvieron de cárceles clandestinas, inclusive casas particulares, pero la falta de la debida certeza impide referirse a ellas o haber realizado procedimientos". Véase Informe Final de la Delegación de Mar del Plata de la CONADEP, op. cit., pp. 3 y 17. A través del Juicio por la Verdad se conoció la existencia de otros lugares que funcionaron como centros clandestinos, como la estancia privada Paraje Los Ortiz. Véase Mora, Belén, Juicios por la verdad histórica..., op. cit.; Andreotti Romanin, Enrique, Memorias en conflicto..., op. cit.

11 Por las características del sistema represivo y la falta de datos, las "listas" definitivas resultan aún complicadas de elaborar. Tomamos la cifra aproximada del informe final de la Delegación Mar del Plata de la CONADEP, sin embargo existen otras investigaciones que llevan el número de desaparecidos en la ciudad a alrededor de 300 personas. Al respecto véase Bozzi, Carlos, Luna Roja..., op. cit. A su vez, en un mural inaugurado en el año 2011 en la Municipalidad de General Pueyrredón, se consignan 436 detenidos desaparecidos, mientras los organismos de derechos humanos sostienen que la cifra es aún mayor. Asimismo, cabe destacar que el propio informe indica que “...una gran cantidad de casos no han sido denunciados por los interesados, hecho que consta personalmente a los miembros de esta Delegación, ya que conocen personalmente a personas y grupos familiares que han sufrido la represión ilegal (...) podemos afirmar sin margen de dudas que hemos recibido sólo una parte del horror represivo. Quizás una cantidad igual o mayor no ha podido registrarse...”. Informe Final de la Delegación de Mar del Plata de la CONADEP, op. cit., p. 4. En el espacio brindado por la prensa local durante la última dictadura al tema, las cifras rondaban los 154 casos de detenidos-desaparecidos registrados o 154 se mencionaba que eran los familiares que los buscaban. Véase a modo de ejemplo El Atlántico. 19/10/1981, La Capital 19/10/1981. Mientras que en 1983 las 
cautiverio $^{12}$, y la conformación de grupos de oposición, denuncia y resistencia a la dictadura como Madres, Abuelas y Familiares de detenidos-desaparecidos.

La Comisión Madres, Abuelas y Familiares de Detenidos Desaparecidos fue la primera organización de derechos humanos en la ciudad, y estaba integrada por familiares de detenidosdesaparecidos que comenzaron a reunirse en 1976 a partir de sus reiterados encuentros en el Grupo de Artillería de Defensa Aérea (GADA) ${ }^{13}$ del Ejército, en las presentaciones de habeas corpus, en las comisarías y en las iglesias de la ciudad, pasando de ser tan solo cuatro mujeres a conformarse un grupo de alrededor de 50 personas, integrado por hermanos, padres, madres y esposas de detenidos-desaparecidos. Las asambleas se hicieron más convocantes a partir de un aviso que publicaron en 1977 en un diario local, invitando a aquellas familias que tuvieran algún integrante desaparecido a participar de sus reuniones. ${ }^{14}$ Una madre recuerda así cómo se acercó a la Comisión:

"En ese momento quedamos muy desorientados y al pasar los días, leo en un diario de la ciudad que los familiares de desaparecidos se reunían en la parroquia San Pedro. Y allí fui y conocí a otras madres en mis mismas circunstancias, preguntándonos ¿quién se llevó a nuestros hijos? ¿Dónde los llevaron? ¿Qué hicieron con ellos?”. ${ }^{15}$

El accionar de la comisión permitió dar visibilidad a la represión desplegada en Mar del Plata y funcionó como un espacio de contención, intercambio de experiencias y de información, recopilación de denuncias, asesoramiento a los nuevos familiares que se acercaban a la comisión y de demanda por el esclarecimiento de las desapariciones en la ciudad. Así, los principales ejes de acción fueron la difusión y denuncia de las violaciones a los derechos humanos y la solidaridad y apoyo mutuos. Desde los primeros años la comisión presentó babeas corpus -rechazados sistemáticamente-, realizó denuncias frente a organismos internacionales de derechos humanos, envió solicitadas al diario La Nación de la ciudad de Buenos Aires y a los diarios locales El Atlántico y La Capital, ${ }^{16}$ envió cartas al exterior -incluso al Papa-, recolectó firmas de ciudadanos, realizó movilizaciones, marchas semanales ${ }^{17}$ y actos en el centro de la ciudad por el esclarecimiento y aparición de los desaparecidos, así como también sus integrantes comenzaron a utilizar pañuelos blancos en las conmemoraciones públicas -las mujeres en la cabeza, mientras

cifras que se vuelcan en estos mismos medios oscilan las 400 personas. También es cierto que el Informe puede incluir más de un caso de detenidos-desaparecidos de otras localidades, como el de José Luis Suarez, oriundo de San Cayetano, detenido-desaparecido en la ciudad de La Plata en 1977, denunciado frente a la CONADEP por su madre mientras la misma vivía en la ciudad de Necochea e incluido en el Informe Final de la Delegación de Mar del Plata.

${ }^{12}$ Entre ellos, los hijos de Laura Adhelma Godoy, militante de Montoneros desaparecida en 1977; de Haydee Susana Valor, militante de Montoneros desaparecida en 1976; de Elizabeth Patricia Marcuzzo, militante de Montoneros desaparecida en 1977; de Susana Beatriz Pegoraro, militante de Montoneros desaparecida en 1977; de Liliana Carmen Pereyra, militante de Montoneros desaparecida en 1977. “¿Dónde están los nietos que faltan?” Folleto de Abuelas de Plaza de Mayo Filial Mar del Plata, 2011, archivo personal.

${ }^{13}$ El GADA 601 era el lugar de operaciones del coronel Barda, jefe, como se mencionó, de la Subzona XV a la que pertenecía Mar del Plata. La institución cumplía diversas funciones jurídico-administrativas y tomaba las denuncias de los familiares de detenidos-desaparecidos. Frente a la indiferencia de la fiscalía federal, éstos recurrían a entrevistarse con el coronel en busca de información sobre sus familiares, quien les informaba $-\mathrm{O}$ no- sobre el estado y el grado de "peligrosidad" de sus parientes y los pasos a seguir. Véase Bozzi, Carlos, Luna Roja..., op. cit.; Mora, Belén, Juicios por la verdad histórica..., op. cit.; Andreotti Romanin, Enrique, Memorias en conflicto..., op. cit.

${ }^{14}$ Entrada del 15/11/2007 del sitio mantenido por el Grupo de Apoyo de Madres de Plaza de Mayo de Mar del Plata http://grupoapoyomadresmdp.blogspot.com.ar/

15 "Madre no hay una sola". La voz de los pañuelos. Asociación Madres de Plaza de Mayo Mar del Plata, Año 2, № 7 , Mar del Plata, septiembre de 2007.

16 Véase a modo de ejemplo La Capital 23/04/1977, 12/1980, 18/10/1981 y 11/1982.

${ }^{17}$ Desde 1978 comenzaron a realizarse alrededor del monumento a San Martín en la Avenida Luro. Luego se optó por caminar desde la catedral a lo largo de la peatonal San Martín hasta la costa y volver, a fin de poder llamar más la atención de los transeúntes. 
que los hombres que las acompañaban los llevaban atados en sus brazos- ${ }^{18}$ Vemos así que la utilización de los "clásicos" pañuelos blancos por parte de las mujeres marplatenses, el mayor símbolo que representa a las Madres, es previa a la conformación de la delegación local. Esto llevó a que medios gráficos -incluidos los locales- en ocasiones utilizaran directamente la denominación Madres de Plaza de Mayo cuando la misma aún no se había conformado en la ciudad. ${ }^{19}$ Consideramos que esta situación puede interpretarse como un desarrollo mimético de sus repertorios discursivos y de acción con respecto a los repertorios que por entonces ya circulaban dentro del movimiento de derechos humanos.

Asimismo, a partir de sus reuniones comenzaron a conformar un pequeño archivo que diera cuenta de cada uno de los desaparecidos de la ciudad. A su vez, utilizaron distintas estrategias de visibilización de la problemática como por ejemplo hacer circular por la ciudad billetes con la inscripción "¿Dónde están los desaparecidos?” -al igual que lo hacían las Madres de Plaza de Mayo en La Plata y la Capital Federal $-^{20}$, asistir a misa utilizando los pañuelos blancos o a conferencias como la realizada por el ex almirante Emilio Massera en 1982 en el Hotel Hermitage de Mar del Plata -en la cual se los colocaron una vez adentro-, o presentarse en las mesas donde figuraban para votar en los comicios de 1983 los desaparecidos de Mar del Plata. Sobre las acciones desplegadas en esos años una integrante de la comisión recuerda: “...íbamos al Ministerio del Interior, al GADA, hacíamos Habeas Corpus, íbamos a la iglesia, a la catedral, hacíamos todo lo que teníamos que hacer." 21

Al principio se reunían semanalmente en el pasaje continuo a la Catedral, en las dependencias del Centro Diocesano de Estudio y Reflexión, y luego en las iglesias Santa Ana -de la que debieron irse por las amenazas recibidas-, San Antonio, San José, Don Bosco, la Iglesia Metodista, la Parroquia de San Pedro y distintas capillas de la ciudad. Así explican algunas madres los cambios de lugar de reunión durante la última dictadura: "Teníamos que correr (...) Todo duraba poco porque enseguida llegaban las amenazas",22.

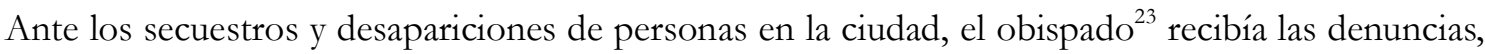
pero desalentaba las reuniones de los familiares y los contactos con las organizaciones de derechos humanos de la capital. Si bien ésta era la postura oficial, algunos sacerdotes

18 Algunos miembros de la Comisión recuerdan haber usado durante algunos meses un clavito del lado del corazón. El uso del pañuelo quizás se haya generalizado una vez que los contactos con las organizaciones de derechos humanos de Capital Federal y La Plata se hicieron más frecuentes. Cabe destacar que en 1981 los agentes de inteligencia de la policía de la provincia de Buenos Aires ya se referían a los pañuelos utilizados por las mujeres y hombres marplatenses como "los clásicos pañuelos blancos que las identifican". Véase a modo de ejemplo Archivo DIPBA. Mesa Ds. Carpeta Varios. Legajo 20.803; La Capital 19/10/1981; El Atlántico 02/04/1983; y la entrada del día 15/11/2007 del sitio mantenido por el Grupo de Apoyo de Madres de Plaza de Mayo de Mar del Plata http://grupoapoyomadresmdp.blogspot.com.ar/

${ }^{19}$ Véase a modo de ejemplo las notas publicadas en el diario El Atlántico en el año 1982. O la publicada por La Voz en la cual se menciona que la marcha del silencio contra la ley de amnistía en Mar del Plata está organizada por las Madres de Plaza de Mayo de esa ciudad. La Voz: 18/03/1983

${ }^{20}$ Véase Gorini, Ulises. La otra lucha. Historia de las Madres de Plaza de Mayo. 1983-1986. Buenos Aires. Norma. 2011

${ }^{21}$ Integrante de la Comisión Madres, Abuelas y Familiares de Detenidos Desaparecidos. Archivo personal.

22 "Madre no hay una sola". La voz de los pañuelos. Asociación Madres de Plaza de Mayo Mar del Plata. Año $1 . N^{\circ} 5$. Mar del Plata. Mayo 2007

${ }^{23}$ En 1957 Mar del Plata fue declarada cabecera del obispado. Cuando falleció Monseñor Enrique Rau en 1972 favorable a las orientaciones del Concilio Vaticano II-, lo sucedió Monseñor Eduardo F. Pironio, quien en 1976 abandonó la feligresía por las constantes amenazas de muerte que recibía por su política de compromiso con los más necesitados y de distribución de la riqueza. Pironio fue reemplazado por Rómulo García, cuya gestión transcurrió durante la última dictadura. Véase Lobato, Mirta Zaida, Mar del Plata de la prehistoria a la actualidad..., op. cit. Las madres recuerdan dicha gestión como no favorable a la problemática que estaban viviendo: "El obispo local, por aquellos años Rómulo García, se negaba a recibirnos, puesto que para él éramos comunistas. Sin embargo, delegó en el padre Pérez la tarea de recibir nuestras denuncias, quien sólo se limitaría a escuchar". Entrada del 15/11/2007 del sitio mantenido por el Grupo de Apoyo de Madres de Plaza de Mayo de Mar del Plata http://grupoapoyomadresmdp.blogspot.com.ar/ 
mantuvieron un compromiso más activo con los familiares de detenidos-desaparecidos. No obstante, esto no alcanzaba para fijar un lugar de reunión. Como lo explica otra militante de la Asociación local:

"Los carros de asalto que se instalaban en las cercanías cada vez que nos reuníamos, las amenazas y las intimidaciones, la represión de los militares y de las fuerzas de seguridad sobre nosotras, la presión sobre sacerdotes y pastores, fueron motivos para peregrinar de una iglesia a la otra". ${ }^{24}$

Algunos de sus miembros empezaron a viajar a Buenos Aires y La Plata desde 1977 en busca de información sobre los desaparecidos de la ciudad y, a partir de estos viajes, comenzaron a establecer contactos con otras agrupaciones de derechos humanos, a través de los cuales pudieron reconocerse dentro de un contexto más amplio ${ }^{25}$. Hacia 1981 esos contactos parecen ser incluso más frecuentes, dado que en la prensa local las mismas manifestaban que estaban en contacto constantemente con las madres de Buenos Aires, ya que viajaban casi todas las semanas. ${ }^{26}$ Una madre recuerda las expectativas con las cuales emprendían esos viajes: "Íbamos a Buenos Aires o a cualquier marcha, íbamos llenas de ilusión, que algo bueno se iba a producir". ${ }^{27}$

Como se desprende de lo anteriormente narrado y como ya han señalado otros autores ${ }^{28}$, en los primeros tiempos, los familiares de detenidos desaparecidos de Mar del Plata -pero no sólo de esta ciudad-actuaron en función de las instituciones eclesiásticas, judiciales y militares, para luego descreer de las mismas al no obtener los resultados esperados. En este sentido, una de las primeras integrantes de la Asociación recuerda en especial la actitud de los eclesiásticos:

"Recorrimos todas las instituciones, militares, policías, ministerios, consulados. En la iglesia donde hacíamos misas y rezábamos nos preguntaban pero también se burlaban, sobre todo el padre Pérez." 29

Con respecto al accionar del poder judicial, también el informe de la delegación de Mar del Plata de la CONADEP dio cuenta de la frustración de los familiares frente al mismo:

"Es generalizada entre los denunciantes la opinión condenatoria del accionar de la justicia, especialmente en el período más crítico del accionar represivo, sosteniéndose que, por encima de tecnicismos jurídicos, el Poder Judicial no garantizó el amparo de sus derechos y por el contrario mostró por lo menos indiferencia ante el drama vivido y la grosera vulneración a los derechos fundamentales conculcados." ${ }^{30}$

El accionar de esta primera organización se extendió hasta mediados de los años 80', momento en que se disolvió tras distintas divisiones que dieron lugar a diversas agrupaciones de derechos

\footnotetext{
${ }^{24}$ Entrada del 15/11/2007 del sitio mantenido por el Grupo de Apoyo de Madres de Plaza de Mayo de Mar del Plata http://grupoapoyomadresmdp.blogspot.com.ar/

${ }^{25} \mathrm{El}$ contacto con otros familiares en la Capital Federal fue de gran importancia para las mujeres marplatenses, en especial para dimensionar el accionar represivo del Estado y la respuesta de la sociedad: "Una vez que viajamos juntas con Angelita, cuando llegamos a la Plaza había tanta gente, tanta, tanta, que nos pusimos a llorar de la emoción, de alegría. Pensábamos «toda esta gente va a empujar, va a pasar algo, vamos a saber algo»". "Madre no hay una sola", La voz de los pañuelos, Asociación Madres de Plaza de Mayo Mar del Plata, Año 1, N 2, noviembre de 2006.

${ }^{26}$ Véase La Capital. 19/10/1981.

27 “"'Madre no hay una sola”, La voz. de los pañuelos, Asociación Madres de Plaza de Mayo Mar del Plata, Año 2, No 10, Mar del Plata, marzo de 2008.

${ }^{28}$ Véase Catela Da Silva, Ludmila, No habrá flores en la tumba del pasado. La experiencia de reconstrucción del mundo de los familiares de desaparecidos, La Plata, Al Margen, 2001; Capitán, M. Belén, “Entre rezos y habeas corpus...”, op. cit.

29 "Madre no hay una sola", La voz de los pañuelos, Asociación Madres de Plaza de Mayo Mar del Plata, Año 1, N 5, Mar del Plata, mayo de 2007

${ }^{30}$ Informe Final de la Delegación de Mar del Plata de la CONADEP, op. cit., p. 7.
} 
humanos en la ciudad. ${ }^{31}$ No obstante, los organismos de la ciudad continuaron realizando actividades en conjunto, como sucedió en otras localidades en las cuales se produjeron desprendimientos de organizaciones originarias. Algunos miembros se alejaron tras la desilusión que significó para ellos el hecho de que no aparecieran los desaparecidos tras la asunción del presidente electo Raúl Alfonsín, tal y como imaginaban que sucedería ${ }^{32}$ y como de hecho había declarado Alfonsín a la prensa y a las Madres de Plaza de Mayo en una entrevista antes de asumir, en la cual había manifestado que creía que había desaparecidos con vida ${ }^{33}$. Otros se desprendieron porque se fueron diversificando los objetivos que se perseguían: mientras algunas mujeres se marcaron como objetivo prioritario encontrar a los bebes y niños desaparecidos junto a sus padres, otras se orientaron a la denuncia de la dictadura y a la búsqueda de verdad y justicia por los crímenes cometidos.

Una integrante de la Asociación de Madres de Plaza de Mayo de Mar del Plata recuerda este período de ruptura en la posdictadura ${ }^{34}$, en un contexto, vale recordar, de gobierno de la UCR en la ciudad, la provincia y el país:

"El año 1984 fue un año muy difícil, pues el grupo de madres y familiares se desmembró. Nosotras constituimos la filial Madres de Plaza de Mayo. Éramos madres de la calle, no de escritorio. El pañuelo era parte de nosotras, no estábamos dispuestas a resignarlo, seguíamos levantando la consigna "Aparición con vida»."35

\footnotetext{
${ }^{31}$ En 1984 se había conformado en la ciudad, además, una delegación de la Asamblea Permanente por los Derechos Humanos. A su vez, se formó una delegación de la Comisión Nacional sobre la Desaparición de Personas, que recopiló denuncias y realizó informes sobre la represión desplegada en Mar del Plata. Esta delegación recibió un legajo compuesto por las denuncias receptadas con anterioridad por la Comisión Madres, Abuelas y Familiares de Detenidos Desaparecidos: "Esta organización había reunido, metódicamente, una gran cantidad de denuncias, las cuales fueron entregadas tanto a esta delegación como a la Comisión Central, lo que motivó que se procediera a su clasificación, quedando radicadas en esta delegación aquellas denuncias vinculadas a la ciudad de Mar del Plata y zona." Informe Final de la Delegación de Mar del Plata de la CONADEP, op. cit., p. 2.

32 Integrante de Madres de Plaza de Mayo filial Mar del Plata. Audios del programa de radio La voz de los pañuelos. Mar del Plata, archivo personal. Agradezco a Jorge Censi por proporcionarme gran parte de los audios utilizados para la escritura de este artículo.

${ }^{33}$ Véase al respecto Gorini, Ulises. La otra lucha..., op. cit. Debe recordarse que no sólo las Madres de Plaza de Mayo consideraban que podían existir desaparecidos con vida. En una solicitada de diciembre de 1983 firmada por Madres, Abuelas, Familiares, CELS y SERPAJ, sostenían que el poder ejecutivo debía “...informar a la población, sin demora, acerca de la suerte de los detenidos-desaparecidos, el reintegro a sus hogares de los que se encuentren con vida y la restitución de los niños a sus legítimas familias." Véase "Organismos de Derechos Humanos Opinan", Diario Clarín, 21/12/1983 (el resaltado es nuestro). Un año después, las Madres escribían: "En los últimos meses, varias Madres de Plaza de Mayo han recibido a través de cartas y llamados, denuncias que certificarían que sus hijos están vivos". Véase “A un año del gobierno radical y de impunidad militar ¿Dónde están los desaparecidos?”, Periódico Madres de Plaza de Mayo, Año I, Nº1, diciembre de 1984. Sin embargo, unos meses antes Alfonsín había declarado: "No creo que podamos hacer nada para devolver lo que las Madres de Plaza de Mayo quieren. Ellas reclaman que sus hijos aparezcan con vida, pero el gobierno se encuentra lamentablemente ante la imposibilidad de dar satisfacción a este legítimo reclamo"; Clarín, 11/08/1984. Más tarde, Hebe de Bonafini le había respondido en otro periódico: "A partir de hoy las Madres ya no podemos confiar para nada en el gobierno”, La Voz,, 07/09/1984.

${ }^{34}$ Coincidimos con la idea sostenida por Teresa Basile de que es posible indagar el presente de la Argentina a partir del par dictadura/posdictadura. Véase Basile, Teresa, "Aproximaciones a la posdictadura en el Cono Sur", Crítica Cultural en Latinoamérica: Paradigmas globales y enunciaciones locales, $\mathrm{N}^{\circ}$ 51, 2000, pp. 115-134. Otros autores también han sostenido que la noción de "transición” y "democracia" deben revisarse. Claudia Feld y Marina Franco sostienen que "transición” fue una categoría nativa para interpretar lo real, una teoría más que una realidad. Por ende, también ellas se refieren al período como "posdictadura" o "gobierno democrático". Véase Feld, Claudia y Franco, Marina (Directoras), Democracia, hora cero. Actores, políticas y debates en los inicios de la posdictadura, Buenos Aires, Fondo de Cultura Económica, 2015

35 Entrada del 15/11/2007 del sitio mantenido por el Grupo de Apoyo de Madres de Plaza de Mayo Mar del Plata http://grupoapoyomadresmdp.blogspot.com.ar/. Palabras muy similares utilizó en una entrevista Sara Mrad para explicar las diferencias entre Familiares y Madres en Tucumán: "Las Madres somos más de lo callejero, de lo público, que de lo administrativo burocrático, y las otras organizaciones no (...)”. Véase Kotler, Rubén (compilador), En el
} 
Cabe recordar que luego de la asunción como presidente de Raúl Alfonsín, las Madres continuaron reclamando la "Aparición con vida" como lo venían haciendo durante la dictadura, al menos desde $1980^{36}$. Con esa consigna exigían que se explicara y expusiera la cadena de hechos y responsables que habían llevado a la desaparición de sus familiares. No sostenerla, significaba para ellas aceptar una muerte abstracta sin responsables. Buscaban que se les explique quiénes, cómo y por qué. En términos literales la consigna negaba la muerte, pero al saberse que había desaparecidos con vida, se convertiría en una de las banderas de la posdictadura. Si no estaban con vida, entonces había responsables, y si había responsables entonces debía actuar la justicia. ${ }^{37}$

La Comisión tenía grandes expectativas con respecto al gobierno elegido democráticamente, pero la rápida desilusión fue una de las causas de los alineamientos que se produjeron posteriormente:

“Cuando asumió Raúl Alfonsín como presidente, en diciembre de 1983, decidimos viajar unas 50 madres y familiares en un micro alquilado. Además, llevábamos una pancarta enorme que decía 'Mar del Plata Presente'. La sacamos cuando llegamos a capital para que todos la vieran. Estábamos contentos y tan esperanzados, casi seguros que alguno de nuestros hijos iba a aparecer con vida, no importaba cuál (...) pero nadie apareció, a pesar que Alfonsín había sostenido -aunque luego se desdijo- que existían desaparecidos con vida." 38

Debe tenerse en cuenta que la creación de la filial marplatense se dio en el marco de un proceso de redefinición y reposicionamiento de la Asociación, abierto tras la asunción a la presidencia del radical Raúl Alfonsín ${ }^{39}$ y de disputa por la conducción de la misma. Las acciones y reivindicaciones de la Asociación se habían definido en confrontación con la dictadura y, en el nuevo contexto -que implicaba nuevas definiciones y con ellas cambios de estrategia-, generaron grandes debates a su interior. En la posdictadura las Madres debatieron sobre sus representaciones en torno al poder, la justicia, el uso de la violencia, la democracia y el rol que debían cumplir en la nueva etapa abierta tras la asunción de un gobierno elegido democráticamente, manifestándose diferentes enfoques que respondían, en parte, a la composición social e ideológica heterogénea de la Asociación. Las contradicciones que emergieron tras estos debates y los relacionados a la creación y alcances de la CONADEP $^{40}$, los pedidos de formación de una comisión parlamentaria bicameral para investigar las violaciones a los derechos humanos, el apoyo o no a la realización del Juicio a las Juntas Militares, la realización

país del sí me acuerdo. Los orígenes nacionales e internacionales del movimiento de derechos humanos argentino: de la dictadura a la transición, Buenos Aires, Imago Mundi, 2014, p. 94.

${ }^{36}$ En un principio se pedía la información sobre qué había pasado con las víctimas bajo la consigna "Vivos o muertos". La consigna "Aparición con vida" aparece en diciembre de 1980 en un comunicado elaborado en Suecia por las madres que habían acompañado a Pérez Esquivel a recibir el Premio Nobel. Véase Jelin, Elizabeth, "La política de la memoria: el Movimiento de Derechos Humanos y la construcción democrática en la Argentina", en AA. VV., Juicio, castigos y memorias. Derechos humanos y justicia en la politica argentina, Buenos Aires, Nueva Visión, 1995; Jelin, Elizabeth, "Certezas, incertidumbres y búsquedas: el movimiento de derechos humanos en la transición", en Feld, Claudia y Franco, Marina (Directoras), Democracia, hora cero..., op. cit.; Iramain, Demetrio. Una Historia de las Madres de Plaza de Mayo, Buenos Aires, Fundación Madres de Plaza de Mayo, 2009.

${ }^{37}$ Véase al respecto Jelin, Elizabeth, "La política de la memoria..." y "Certezas, incertidumbres y búsquedas...", op. cit.; Gorini, Ulises. La otra lucha..., op. cit.

${ }^{38}$ Entrada del 15/11/2007 del sitio mantenido por el Grupo de Apoyo de Madres de Plaza de Mayo Mar del Plata http://grupoapoyomadresmdp.blogspot.com.ar/.

${ }^{39}$ Claramente no sólo las Madres de Plaza de Mayo modificaron en la transición sus alineamientos y estrategias. El resto de las organizaciones de derechos humanos no estuvieron exentas de debates, rupturas y conflictos. Véase Jelin, Elizabeth, "La política de la memoria..." y "Certezas, incertidumbres y búsquedas...", op. cit.; Kotler, Rubén (compilador), En el país del sí me acuerdo..., op. cit.

40 Véase Escher, Federico, "La Asociación Madres de Plaza de Mayo durante la transición democrática en la Argentina, controversia en torno a la CONADEP”, Ponencia presentada en V Jornadas de Jóvenes Investigadores. Universidad de Buenos Aires. 2009. 
o no de las Marcha de la Resistencia, la utilización o no del método de escrache $e^{41}$, la aceptación o no de las indemnizaciones previstas por la ley 23.466 sancionada en 1986, el reconocimiento o no de la militancia de sus hijos y las exhumaciones o no de tumbas $\mathrm{NN}$, sumado a las tensiones por la forma de conducir de la presidenta de la asociación -en la que algunas integrantes veían rasgos de autoritarismo y personalismo-, llevaron a la división de las Madres en 1986. Estos debates estuvieron presentes en Mar del Plata, por lo que también en dicha ciudad se conformó una agrupación de Madres de Plaza de Mayo - Línea Fundadora además de la filial de la Asociación liderada por Hebe de Bonafini que analizamos aquí. De esta forma, en el marco de los debates internos y de las polémicas con otros sectores del movimiento de derechos humanos, se desarrollaron dos identidades político-ideológicas que desembocaron en la división de una agrupación que para 1986 contaba con 23 filiales en todo el país ${ }^{42}$. Las diferencias ideológicas se hicieron evidentes cuando, tras la división, la Asociación convocó a la sexta marcha de la resistencia bajo las consignas "No a las exhumaciones", "No a la reparación económica", "No a los homenajes póstumos".

\section{La Asociación Madres de Plaza de Mayo de Mar del Plata}

Ciertamente, el movimiento de derechos humanos es un movimiento diverso y heterogéneo. A partir de las distintas investigaciones de los últimos años que lo tienen como objeto de análisis, podemos decir que el mismo ha tenido recorridos diversos de acuerdo a las geografías donde se desarrolló, las ideologías que confluyeron en su seno, las estructuras de oportunidades políticas locales y los recursos movilizables, todo lo cual marcó diferencias en cuanto a los desafíos, logros, experiencias y periodizaciones.

La Asociación Madres de Plaza de Mayo filial Mar del Plata nació en 1984 luego de la división de la Comisión Madres, Abuelas y Familiares de detenidos-desaparecidos ${ }^{43}$ que, como mencionáramos, fue la primera organización defensora de los derechos humanos de la ciudad, formada entre 1976 y 1977 y cuyo accionar se extendió hasta mediados de los años ' $80{ }^{44}$

\footnotetext{
${ }^{41}$ En los años '80 las Madres realizaron algunas acciones de denuncia pública como acto de sanción ética y política que algunos autores toman como antecedentes de la generalización de dichas acciones en los años '90, fundamentalmente por parte de la agrupación HIJOS. A modo de ejemplo puede señalarse el "escrache" realizado en el Congreso de la Nación, a los diputados radicales en general y al presidente del bloque radical, Cesar Jaroslavsky, en particular, tras el debate del proyecto oficial de reforma al código de justicia militar en 1984. Sin embargo, no todas las Madres estaban de acuerdo con el método de "escrache" como práctica política de enfrentamiento cara a cara, lo cual fue motivo de debate al interior de la Asociación. Las Madres sostenían públicamente por entonces que, frente a la inacción y lentitud de la justicia, había que identificar a los represores para efectuar una condena moral: "Nosotras vamos a pintar las paredes del país, cada pañuelo blanco pintará un nombre de un asesino, de un represor, de un torturador. No vamos a permitir que se olvide. Nadie los va a publicar, pero las Madres los vamos a dar a conocer, día por día, hora por hora, estaremos en la puerta de sus casas, en la esquina de sus casas, en sus trabajos, señalándolos". Declaraciones de Hebe de Bonafini en un acto en Parque Lezama, 16/09/1984 citadas en Gorini, Ulises, La otra lucha..., op. cit., p. 199 y en Escher, Federico, "La Asociación Madres de Plaza de Mayo...”, op. cit., p. 15. En declaraciones al año siguiente, con motivo de otra Marcha de la Resistencia, la presidenta de la Asociación sostuvo: "Y si no conseguimos justicia, pintaremos sus casas, los perseguiremos, nos pondremos en las esquina de sus casas y vigilaremos a sus hijos”, 11/12/1985, citado en Gorini, Ulises, La otra lucha ..., op. cit., p. 482.

42 Véase Gorini, Ulises, La otra lucha..., op. cit.

${ }^{43}$ Dicha división no fue perdida de vista por los agentes de inteligencia de la policía de la provincia de Buenos Aires, puesto que en sus informes se las diferencia de la Comisión Madres, Abuelas y Familiares de DetenidosDesaparecidos de la que algunas de sus integrantes habían sido parte, aclarando que mientras una era una formación local la otra se había conformado como una filial de la nacida en Buenos Aires. Véase CPM. Fondo DIPPBA. División Central de Documentación, Registro y Archivo. Mesa "De". Carpeta Entidades Varias. 541. Tomo 1; CPM. Fondo DIPPBA. División Central de Documentación, Registro y Archivo. Mesa Ds. Carpeta Varios. Legajo 22.954

${ }^{44}$ Como se mencionó, también en otras localidades el proceso de nacimiento de Madres de Plaza de Mayo fue a partir del desprendimiento o distanciamiento de otra organización en los años '80. En el caso de Santa Fe, algunas militantes del movimiento de derechos humanos local formaron en 1987 Madres de Plaza de Mayo en la línea de la Asociación liderada por Hebe Pastor de Bonafini, hasta el año 2001 en que se desvincularon. En el caso de Rosario,
} 
Consideramos que su conformación obedece a dinámicas tanto nacionales como locales. Si bien puede hablarse de una política de expansión en la posdictadura de la Asociación Madres de Plaza de Mayo de Buenos Aires hacia otras ciudades del país, no es menos cierto que la misma se conformó en la ciudad de Mar del Plata a raíz también de las disputas, las alianzas y las estructuras de oportunidades políticas locales. Los debates producidos y los objetivos buscados, derivaron en redefiniciones y reposicionamientos del movimiento de derechos humanos local tras la asunción de Ángel Roig en la ciudad y Raúl Alfonsín en la presidencia de la nación.

Desde sus inicios la Asociación estuvo conformada en esta ciudad por mujeres de diversos orígenes, trayectorias, participación y militancia ${ }^{45}$. Las mismas continuaron con las actividades de averiguación de datos, recopilación de información, contención y denuncia que venían realizando y, con los años, fueron ampliando el repertorio de sus acciones colectivas. Una de las acciones de visibilidad desplegadas por la asociación fue, al igual que en otras localidades del país, la marcha de los días jueves, que en el caso de Mar del Plata se realiza desde 1984 frente a la Catedral, ubicada en la peatonal San Martín, en pleno centro cívico y comercial. También realizaron volanteadas, campañas de firmas, conferencias de prensa, charlas-debate, festivales y exhibiciones de películas. Otras acciones fueron repetir campañas realizadas en Buenos Aires como "Dé su mano por un desaparecido" en 1985, o manifestaciones en ocasiones concretas como la realizada en el marco de la Conferencia de Jefes de Ejércitos Latinoamericanos en 1987 en el Hotel

la delegación local de Madres de Plaza de Mayo se formó en 1985 a partir de militantes de Familiares de Desaparecidos y Detenidos por Razones Políticas y Gremiales de Rosario. En el caso de provincias del sur del país, la Asamblea Permanente por los Derechos Humanos “Alto Valle y Neuquén” también sufrió una fractura que dio origen a la delegación local de la Asociación de Madres de Plaza de Mayo en 1982. En el caso de Tucumán, la organización Familiares de detenidos por Razones Políticas, primera organización de derechos humanos de dicha localidad, sufrió una primera división en 1981 que dio origen a la agrupación Madres de Detenidos Desaparecidos de Tucumán, en línea con la Asociación liderada por Hebe. Para ampliar véase Kotler, Rubén (compilador), En el país del si me acuerdo..., op. cit.; Azconegui, Ma. Cecilia, "De madres de desaparecidos a Madres de Plaza de Mayo. La definición de identidades en el seno de la Asamblea Permanente por los Derechos Humanos filial Neuquén y Alto Valle”, XII Jornadas Interescuelas Departamentos de Historia, San Carlos de Bariloche, 2009; Alonso, Luciano, Luchas en plazas vacias de sueños. Movimiento de derechos humanos, orden local y acción antisistémica en Santa Fe, Rosario, Prohistoria, 2011; Scocco, Marianela, El viento sigue soplando. Los origenes de Madres de Plaza 25 de Mayo de Rosario (19771985), Rosario, Último Recurso, 2016.

45 En el caso de Mar del Plata, como en Tucumán, no prevaleció el vínculo maternal para ser parte de la delegación. Así, una de sus integrantes más activas es esposa de un detenido desaparecido en la ciudad, y no madre como la mayoría de las militantes de la organización. A su vez, como en otras localidades, fue frecuente que un agente individual participara bajo más de un sello organizativo. Así, otra militante activa lo es también de la filial local de Abuelas de Plaza de Mayo, organización gracias a la cual pudo identificar a su nieto hace diez años. En cuanto a sus ocupaciones paralelas a la militancia en la Asociación al momento de constituirla, nos encontramos con que se trataba de amas de casa, estudiantes, hoteleras, secretarias, tanto con experiencia política como sin experiencia política, en su mayoría de clase media, pero también de sectores más populares. Aquellas que poseían una experiencia política previa eran más escuchadas y respetadas que aquellas que no la poseían. Como recuerdan las Madres a una militante de la Asociación fallecida en 1995: "Era una gran compañera y luchadora, sus opiniones eran valoradas por nosotras, pues era una de las pocas que tenía cierta experiencia política". "Madre no hay una sola". La voz de los pañuelos, Asociación Madres de Plaza de Mayo Mar del Plata, Año 2, $\mathrm{N}^{\circ}$ 9, enero de 2008. Asimismo, la experiencia en torno a la militancia del familiar no fue vivida de una misma manera: algunas sabían donde militaban sus familiares -PST, PT, UES, Vanguardia Comunista, Montoneros- y otras no. Una integrante recuerda: "Algunas podían tener su idea política. Por ejemplo Nelly andaba con sus hijas, ella vivió la militancia de sus hijas, yo no la viví. Adriana militaba en La Plata y yo estaba acá y la militancia de ella fue muy corta, yo no estaba interiorizada de nada. Muchas madres sabían que sus hijos militaban; yo no sabía nada, me fui enterando después." Integrante de Madres de Plaza de Mayo Filial Mar del Plata y Abuelas de Plaza de Mayo Filial Mar del Plata -agradezco al periodista Jorge Censi por brindarme el audio-. En algunos casos al familiar lo secuestraron previo al golpe de Estado, en otros casos en 1976, 1977 o 1978. Algunas estaban en el momento en que se lo llevaron, mientras que otras se enteraron después. Algunas madres fueron secuestradas y liberadas a las semanas o meses, mientras que una madre marplatense de origen español permanece desaparecida desde su secuestro en 1977. Por otra parte, mientras algunas habían imaginado la posibilidad de un nuevo golpe militar tras la muerte de Juan Domingo Perón, otras no lo imaginaban en absoluto. Véase "Madre no hay una sola", op. cit. 
Provincial de Mar del Plata ${ }^{46}$. Asimismo, las integrantes de la filial local participaban de los encuentros realizados en las distintas filiales de la Asociación, en tanto eran ámbitos de intercambio de propuestas y de debates de ideas y planes a seguir. En este sentido, el primer Encuentro Nacional -instancia surgida durante los últimos años de la dictadura- de las Madres de Plaza de Mayo que se llevó a cabo en Mar del Plata fue en $1985^{47}$.

En relación al vínculo con las representantes de Capital Federal, cabe destacar que en los primeros años de conformación de la Asociación en Mar del Plata, las visitas a la ciudad de Hebe Pastor de Bonafini ${ }^{48}$, presidenta de la Asociación Madres de Plaza de Mayo, fueron reiteradas en 1985, 1986 y $1987^{49}$. Las mismas tuvieron repercusión en la prensa escrita ${ }^{50}$ a la vez que fueron registradas también por agentes policiales, fundamentalmente las relacionadas con las manifestaciones en contra de las exhumaciones en Cementerio Parque y su interrupción por parte de las integrantes de la Asociación marplatense y Hebe de Bonafini en el año $1985^{51}$.

Este episodio puede ser utilizado para reflejar la relación entre la filial y el resto de las organizaciones defensoras de los derechos humanos de la ciudad. La orden judicial había sido dispuesta ese año por el juez Pedro Hooft ${ }^{52}$, a quien por entonces la Asociación ya reconocía como cómplice de la dictadura. Esta actitud provocó disputas al interior del movimiento de derechos humanos local, dado que Abuelas de Plaza de Mayo, Familiares de detenidosdesaparecidos, la Comisión Madres, Abuelas y Familiares de Detenidos-Desaparecidos, y los abogados miembros de la delegación Mar del Plata de la CONADEP ${ }^{53}$, rechazaron la actitud de Madres de Plaza de Mayo de frenar la orden judicial. La misma había sido promovida por distintos familiares de detenidos desaparecidos de la ciudad ${ }^{54}$, especialmente por Abuelas de Plaza de Mayo, en un intento por comprobar, a partir de las exhumaciones, el parto de una de las

\footnotetext{
46 Véase "Derechos Humanos: Tensa Marcha en Mardel”, Crónica, 17/11/1987.

47 Véase Gorini, Ulises, La otra lucha..., op. cit.

${ }^{48}$ Mar del Plata no fue la única ciudad que registró su presencia en la posdictadura. Véase Kotler, Rubén. op. Cit.

${ }^{49}$ Las visitas fueron frecuentes y fueron las que más repercusiones tuvieron por ser la presidenta de la Asociación, pero durante estos años también se registró la presencia de una Madre proveniente de Tucumán y de varias Madres provenientes de la Capital y de La Plata.

${ }^{50}$ Véase a modo de ejemplo La Voz: 15/11/1984; La Prensa 11/03/1985; La Razón 11/03/1985 y 13/03/1985; Diario Popular 11/03/1985 y 13/03/1985; La Voz 11/03/1985 y 15/03/1985; Tiempo Argentino 15/03/1985; La Nación 12/03/1985, 13/03/1985, 16/03/1985 y 21/03/1985; Crónica 17/11/1987; El Atlántico 11/03/1985 y 25/05/1987; La Capital 11/03/1985

51 Véase CPM. Fondo DIPPBA. División Central de Documentación, Registro y Archivo. Mesa Ds. Carpeta Varios. Legajo 22.954; CPM. Fondo DIPPBA. División Central de Documentación, Registro y Archivo. Mesa Ds. Carpeta Varios. Legajo 24.700; CPM. Fondo DIPPBA. División Central de Documentación, Registro y Archivo. Mesa Ds. Entidades Varias. Legajo 541. Tomo I

${ }^{52}$ El juez federal Pedro Federico Cornelio Hooft, fue nombrado en 1976 por decreto del gobernador de facto de la Provincia de Buenos Aires, general Ibérico Saint Jean. Acusado por delitos de lesa humanidad durante la última dictadura, Hooft se desempeñó como profesor titular de la cátedra "Filosofía del Derecho" en la Facultad de Derecho de la Universidad Nacional de Mar del Plata hasta su renuncia en 2007. En 2013 fue imputado y procesado. A comienzos de 2006 había sido denunciado por la Secretaria de Derechos Humanos de la Nación ante la justicia federal de Mar del Plata, en base a los testimonios obtenidos en el Juicio por la Verdad en las audiencias de marzo de 2001 y algunos organismos de derechos humanos se sumaron como querellantes. Madres de Plaza de Mayo Filial Mar del Plata ha denunciado el accionar de Hooft a lo largo de los años por distintos medios. Véase a modo de ejemplo La voz de los pañuelos. Asociación Madres de Plaza de Mayo Mar del Plata, Año 1, N 1, septiembre de 2006; Año 1, No 2, noviembre de 2006; Año 1, $\mathrm{N}^{\circ}$ 6, julio de 2007; Año 2, $\mathrm{N}^{\circ}$ 8, noviembre de 2007.

${ }^{53}$ La Delegación Mar del Plata de la CONADEP estaba integrada por Armando Rodolfo Fertitta, María Luisa Turón de Toledo, Enzo Giustozzi, Juan Carlos Wlasic, Marcelo Andres Insaurralde, Rodolfo Van Benthem, Oscar Antonio Huerta y Rabino Guillermo Bronstein. Véase Informe Final de la Delegación de Mar del Plata de la CONADEP, op. cit.

${ }^{54}$ Dicha exhumación había sido solicitada en la causa que investigaba el paradero de Adriana Frigerio, Liliana Pereyra -embarazada al momento del secuestro- y Alberto Fonseca, por los abogados Wlasic, Insaurralde y Fertitta, quienes integraran la delegación local de la CONADEP.
} 
desaparecidas de la ciudad que estaba embarazada al momento del secuestro. ${ }^{55} \mathrm{El}$ episodio, que fue ampliamente difundido los días siguientes ${ }^{56}$, refleja las disputas y tensiones en torno a los desaparecidos que se venían desarrollando al interior del movimiento de derechos humanos. ${ }^{57}$

Debe tenerse en cuenta que las exhumaciones masivas de NN entre 1984 y 1985 contradecían una de las consignas más importantes de la asociación, la de "Aparición con vida". Al decretar la muerte de la víctima comenzaba a correr el plazo de prescripción del delito, puesto que se abandonaba la figura jurídica de "privación ilegítima de la libertad" que se aplicaba a los desaparecidos. Para las Madres, las exhumaciones respondían a un objetivo político, terminar con el drama de los desaparecidos, puesto que a partir de la exhumación y su posible identificación dejarían de ser desaparecidos y constituirían simples casos de homicidio, sin determinación de las circunstancias del hecho. En términos políticos, consideraban que la búsqueda individual las sustraería de la lucha política colectiva y, en términos jurídicos, que servirían para que comenzara a correr el plazo de prescripción de los crímenes.

$\mathrm{Al}$ año siguiente, en 1986, el juez Jorge Horacio García Collins, a cargo del Juzgado Federal en lo Criminal y Correccional $\mathrm{N}^{\circ} 4$ de Mar del Plata, ordenó la prisión preventiva de Hebe de Bonafini por los sucesos de Cementerio Parque, por desacato y resistencia a la autoridad. En esa oportunidad, sin embargo, el movimiento de derechos humanos se solidarizó con la presidenta de la Asociación, lo cual muestra que se trataba de una relación dinámica, con aislamientos y acercamientos $^{58}$. Cabe destacar que en la manifestación realizada en Mar del Plata por las Madres de Plaza de Mayo, encabezada por la presidenta de la delegación local, Beatriz Serebrinsky de Rubinstein, con la participación de Madres provenientes de La Plata y Capital Federal, junto a otras organizaciones de derechos humanos, agrupaciones políticas y simpatizantes no encuadrados, las mismas fueron agredidas, como sucedió en otras ocasiones desde su

${ }^{55}$ Véase CPM. Fondo DIPPBA. División Central de Documentación, Registro y Archivo. Mesa Ds. Carpeta Varios. Legajo 24.700

56 Véase Diario Popular, 11/03/1985, 13/03/1985; La Prensa. 11/03/1985; La Razón. 11/03/1985, 13/03/1985; La Voz: 11/03/1985, 15/03/1985; Tiempo Argentino. 15/03/1985; La Nación. 12/03/1985; 13/03/1985, 16/03/1985, 21/03/1985, La Capital. 11/03/1985; El Atlántico. 11/03/1985.

57 El primer caso denunciado de entierros de desaparecidos como NN fue en octubre de 1982. Un grupo de familiares de detenidos-desaparecidos realizó una presentación en la justicia pidiendo que se investigara la inhumación de personas no identificadas en el cementerio de Grand Bourg, localidad bonaerense, ubicada en las proximidades a Campo de Mayo. Luego se descubrirán otras en Capital Federal, Mar del Plata y Córdoba. Según Juan Gandulfo resultó de gran relevancia el rol activo que las Madres de Plaza de Mayo asumieron en busca de que el caso de Grand Bourg tuviera visibilidad y obtuviera trascendencia política. Las mujeres miembros de esta organización concurrieron al cementerio los dos días posteriores a la realización de la denuncia. Así, con motivo de la presencia de la Madres en el cementerio, los periodistas de los principales periódicos llegaron al lugar y comenzaron a informar sobre el caso. El 25 de octubre habían asistido al palacio municipal de General Sarmiento en San Miguel, y habían sido recibidas por el intendente, José Lombardo. Su presencia logró que la investigación judicial obtuviera relevancia política que colocaba así al caso en el centro de la agenda pública. Véase Gorini, Ulises, La rebelión de las Madres. Historia de las Madres de Plaza de Mayo.1976-1983, Buenos Aires, Norma., 2006; Gandulfo, Juan, "Justicia y Derechos Humanos: El fuero penal de la provincia de Buenos Aires durante la transición democrática. El expediente judicial del caso de las tumbas de NN de Grand Bourg (1982-1983)", VII Jornadas de Sociología. Universidad Nacional de La Plata. 2012; Gandulfo, Juan, El caso de las tumbas de NN de Grand Bourg. La justicia y los organismos de derechos humanos en la transición a la democracia, Tesis de Maestría en Ciencias Sociales. Universidad Nacional de General Sarmiento, disponible en línea en: http://www.ungs.edu.ar/ms ungs/wpcontent/uploads/2015/08/Tesis Gandulfo.pdf; Gandulfo, Juan, "Los límites de la justicia. La causa por las tumbas de NN del cementerio de Grand Bourg”, en Feld, Claudia y Franco, Marina (Directoras), Democracia, hora cero..., op. cit. En Mar del Plata, la Comisión Madres, Abuelas y Familiares de Detenidos-Desaparecidos realizó una concentración frente a la Catedral en octubre de 1982 para reclamar justicia acerca del descubrimiento de cadáveres NN en el cementerio Grand Bourg. Véase Mesa Ds. Carpeta Varios. Legajo 20.803.

58 Véase "Documento de apoyo a Bonafini", Clarín, 02/03/1986; "Hubo una protesta por la prisión preventiva de Hebe de Bonafini”, La Nación, 03/03/1986. La Dirección de Inteligencia de la Policía de la Provincia de Buenos Aires también dio cuenta del apoyo recibido por parte de otros organismos de derechos humanos. Véase al respecto CPM. Fondo DIPPBA. División Central de Documentación, Registro y Archivo. Mesa Ds. Carpeta Varios. Legajo 24.700 
conformación. ${ }^{59}$ Dicha manifestación se llevó adelante con el objetivo de rechazar la prisión preventiva y se realizó frente a la sede de la departamental de Mar del Plata del Poder Judicial de la Provincia de Buenos Aires, sede del juzgado a cargo de García Collins y según la fuente que se tome la convocatoria rondó entre las 60 y las 120 personas. $^{60}$

Tras los episodios de Cementerio Parque volvió a debatirse la postura en torno a las exhumaciones y si los procedimientos no habían llevado a transformar en adversarios a familiares y abogados defensores de los derechos humanos en la ciudad y en general. Esto llevó a que constara en actas de la Asociación que “...con respecto a las exhumaciones Madres marca una línea: la no exhumación sin haber sido juzgado y condenado antes a los asesinos. Pero se deja en libertad a la madre que quiera exhumar."

Por otra parte, en los primeros años de conformación, tanto las integrantes de la Asociación como personajes vinculados a otras agrupaciones del movimiento de derechos humanos a nivel local, sufrieron una serie de amenazas y atentados vinculados al accionar de agentes locales ligados a la represión durante la dictadura, incluidas las padecidas en fechas conmemorativas como el 24 de marzo. A modo de ejemplo, debemos mencionar que la representante de las Madres a nivel local en los primeros tiempos de la filial, Beatriz Serebrinsky de Rubinstein, recibió en su domicilio en 1984 una encomienda que contenía huesos humanos por un grupo identificado como "Comando Legión Cóndor Escuadra 33 Mar del Plata". En la nota que acompañaba dicha encomienda, el comando señalaba que eran los restos de su hija Patricia, desaparecida en 1977 en La Plata junto a su esposo Carlos Simons, aunque luego de los análisis se determinó que no correspondían a la misma. El hecho suscitó expresiones de repudio y solidaridad del resto del movimiento de derechos humanos de la ciudad con la presidenta local de Madres de Plaza de Mayo. ${ }^{62}$ Esto puede indicarnos, como mencionáramos, que la relación de la asociación con el resto del movimiento local no era sólo de tensión sino también de solidaridad.

Este mismo grupo de ultraderecha también realizó amenazas a integrantes de la Asamblea Permanente por los Derechos Humanos (APDH) filial Mar del Plata, efectuó atentados en domicilios particulares y amenazas telefónicas a miembros de la delegación local de la CONADEP, y se adjudicó el secuestro del empresario Osvaldo Sivak ${ }^{63}$. Con respecto a este último caso, el comando sostenía que estaba vivo en la ciudad de Mar del Plata y que su vida

\footnotetext{
59 "Nos arrojaron huevos, piedras, bolsas con agua en su interior y elementos en polvo y además nos insultaron constantemente." Declaraciones en La Capital 06/03/1986.

60 Véase "Mardel: incidentes por la Bonafini", La Razón, 06/03/1986; La Capital, 06/03/1986; El Atlántico, 06/03/1986. La Dirección de Inteligencia de la Policía de la Provincia de Buenos Aires también dio cuenta de dicha manifestación. Véase CPM. Fondo DIPPBA. División Central de Documentación, Registro y Archivo. Mesa Ds. Carpeta Varios. Legajo 24.700. Respecto a la capacidad de convocatoria o apoyos que recibieron en este período, una integrante de la Asociación marplatense recuerda: "Con el retorno de la democracia, la gente participó mucho más, estábamos más acompañadas". "Madre no hay una sola". La voz de los pañuelos. Asociación Madres de Plaza de Mayo Mar del Plata, Año 2, N 7, Mar del Plata, septiembre de 2007.

${ }^{61}$ Libro de actas de la Asociación Madres de Plaza de Mayo, 02/04/1985, p. 275.

${ }^{62}$ Véase El Día. 14/11/1984, 15/11/1984, 16/11/1984; La Voæ. 14/11/1984, 15/11/1984; La Razón 14/11/1984; Diario Popular 14/11/1984, 15/11/1984, 16/11/1984, 18/11/1984; Crónica15/11/1984, 16/11/1984; CPM. Fondo DIPPBA. División Central de Documentación, Registro y Archivo. Mesa Ds. Carpeta Varios. Legajo 22.871. Mónica, hija de Beatriz e integrante del Grupo de Apoyo de Madres de Plaza de Mayo de Mar del Plata, aún recuerda el episodio como uno de los más traumáticos para su familia. Conversaciones con la autora en Mar del Plata en noviembre de 2012.

63 Véase CPM. Fondo DIPPBA. División Central de Documentación, Registro y Archivo. Mesa Ds. Entidades Varias. Legajo 541. Tomo I; CPM. Fondo DIPPBA. División Central de Documentación, Registro y Archivo. Mesa Ds. Carpeta Varios. Legajo 25.443; CPM. Fondo DIPPBA. División Central de Documentación, Registro y Archivo. Mesa Ds. Carpeta Varios. Legajo 22.871
} 
dependía de lo que sucediera en el Juicio a las Juntas Militares que se estaba desarrollando por entonces ${ }^{64}$.

Por otra parte, si bien las Madres habían hecho del apartidismo uno de los principios fundantes de la Asociación ${ }^{65}$, especial atención le dieron los agentes policiales al registro de otras agrupaciones o partidos políticos que acompañaron a las Madres de Mar del Plata en sus actividades en los primeros años. Cabe destacar que en 1983, cuando aún existía la Comisión Madres, Abuelas y Familiares de detenidos-desaparecidos, la misma reafirmaba también una posición apartidista:

"Nunca nos ha interesado conocer la religión o ideología de los detenidos-desaparecidos. Que quede claro que no estamos mezclados con ningún partido político; no obstante, en este momento, contamos con el apoyo de casi todos."

Esta lectura en clave de participación nos permite acercarnos al clima político en esta ciudad turística $^{67}$ de rango medio ${ }^{68}$ de la Provincia de Buenos Aires. En este sentido, podemos observar que intervinieron en distintas actividades realizadas por las Madres en el período aquí analizado en Mar del Plata, agrupaciones juveniles - la Federación Juvenil Comunista, la Juventud Socialista, la Juventud Peronista, la Juventud Radical del Movimiento de Renovación y Cambio-, organizaciones estudiantiles - la Juventud Universitaria Peronista, la Federación Universitaria Marplatense, la Federación de Estudiantes Secundarios, el Centro de Estudiantes de Artes Visuales, distintas agrupaciones de escuelas de enseñanza media de la ciudad como la Agrupación de Estudiantes Secundarios 16 de septiembre o el Centro de Estudiantes de la Escuela de Educación Media Número 1-, otras agrupaciones del movimiento de derechos humanos local Abuelas de Plaza de Mayo y Familiares de Detenidos-Desaparecidos-, organizaciones de trabajadores -la Asociación de Trabajadores del Estado y el gremio de Luz y Fuerza Mar del Plata- y distintas agrupaciones y partidos políticos como el Movimiento Socialista de los Trabajadores, el Movimiento Todos por la Patria, el Partido Obrero, el Partido Intransigente, el Partido Comunista, el Partido del Trabajo y el Pueblo, el Partido Justicialista, el Movimiento de Fondos Cooperativos, el Movimiento al Socialismo, Intransigencia y Movilización Peronista, el Centro de Residentes Chilenos y el Frente Argentino por la Liberación. ${ }^{69}$

${ }^{64}$ El empresario Osvaldo Sivak, presidente de la Buenos Aires Building, fue secuestrado y liberado en dictadura y vuelto a secuestrar durante el gobierno de Alfonsín en 1985. El "caso Sivak" fue uno de los más resonantes desde el restablecimiento democrático. En el año 2014 la Corte Suprema de Justicia dejó firme la condena civil contra el Estado nacional por el secuestro y homicidio del empresario, cometido por una banda integrada por oficiales de la Policía Federal. Para más información sobre este caso véase http://memoria.telam.com.ar/noticia/sivak-fuesecuestrado-por--la-banda-de-los-comisarios-n1331 y http://memoria.telam.com.ar/noticia/primer-secuestro-desivak-fue-crimen-de-lesa-humanidad n1330

65 "Nosotras sabemos que lo que hacemos es bien político, pero no es partidista, y no tenemos ninguna relación especial con ningún partido político", Hebe de Bonafini en "Bonafini: responden como la dictadura", Clarín, 09/01/1984. Véase también Véase Gorini, Ulises, La rebelión de las Madres..., op. cit.

66 "Por la aparición con vida. Madres marplatenses marcharán el viernes", La Voz, 30/03/1983.

${ }^{67}$ Para analizar los rasgos turísticos de la ciudad véase entre otros Lobato, Mirta Zaida, Mar del Plata de la prehistoria a la actualidad..., op. cit.; Diario La Capital, 100 años..., op. cit., AA.VV. Mar del Plata. Una historia urbana, Fundación Banco Boston, Buenos Aires, 1991; Álvarez, Norberto; Rustoyburu, Cecilia; Zuppa, Graciela, Pasado y Presente de la Mar del Plata social. Coloquio I, Eudem, Mar del Plata, 2005; Pastoriza, Elisa, "Estado, gremios y hoteles. Mar del Plata y el peronismo", Estudios Sociales No 34, 2008; Roccatagliata, Juan Alberto (Coord.), Mar del Plata y su región. Sociedad argentina de estudios geográficos, Buenos Aires, 1984; Sebreli, Juan José, Mar del Plata, el ocio represivo, Editorial Leonardo Buschi, Buenos Aires, 1984.

${ }^{68}$ La población total fue aumentando de 317.444 habitantes en el Censo de 1970, a 434.160 en el Censo de 1980, 532.845 en el Censo de 1991, 564.056 en el Censo de 2001, hasta 614.350 en el Censo de 2010. Datos disponibles en http://www.indec.mecon.ar/ o en http://www.mardelplata.gob.ar/

${ }^{69}$ Véase a modo de ejemplo La Razón, 06/03/1986; El Atlántico, 02/04/1983; La Voz, 18/03/1983 y 30/03/1983; Crónica, 17/11/1987; véase también CPM. Fondo DIPPBA. División Central de Documentación, Registro y Archivo. Mesa Ds. Carpeta Varios. Legajo 20.803. Tomo 8, 9 y 10; CPM. Fondo DIPPBA. División Central de 
Debe recordarse que la reivindicación o no de la militancia de los desparecidos fue tema de debate al interior de las Madres, entre quienes sostenían que había que explicitar la condición de militantes políticos y/o sociales y quienes pensaban que había que poner el énfasis en su condición de víctima de la represión. Finalmente se optó por hacer referencia a sus luchas, aunque de forma bastante general, sin alusiones específicas a las organizaciones a las cuales pertenecían, para recién más tarde hacer menciones más explícitas sobre la militancia de los detenidos-desaparecidos ${ }^{70}$. Asimismo, en el período de transición no sólo las Madres, si no el movimiento de derechos humanos en general, comenzó a contar con mayor apoyo de partidos políticos. ${ }^{71}$ Esto se vio reflejado también en Mar del Plata, como lo demuestra el registro de las organizaciones que acompañaron las actividades de las Madres y las expresiones de las mismas. ${ }^{72}$ Como ya ha sido señalado por otros autores, las Madres encarnaban un punto de inflexión en relación con ciertas tradiciones políticas que conmovía a los sectores progresistas y de izquierda. ${ }^{73}$

\section{Reflexiones finales}

Como ya han señalado otros autores, las acciones y la efectividad de los movimientos sociales se pueden comprender a partir de entender la interacción de distintos niveles de estructuras de oportunidades nacionales, regionales e internacionales y cómo estas interactúan y producen resultados concretos. Asimismo, consideramos que los estudios que hacen foco en lo local permiten complejizar las explicaciones sobre un tema específico, el cual, en este caso, ha sido estudiado, hasta hace algunos años, centrándose en la realidad capitalina, simplificando de esta manera lo acaecido en otros espacios. Esto es relevante si tenemos en cuenta que la escala en la cual actúan los actores sociales, construye sus límites y sus identidades. Así, cada localidad tendrá su especificidad pese a los puntos de contacto con otras realidades. ${ }^{74}$ Los desarrollos locales presentan así diferencias en las periodizaciones, desafíos, logros y experiencias respecto de los desarrollos nacionales y globales. Es posible sostener que las formas y temporalidades del movimiento en las distintas localidades variaron en función de las diversas tradiciones ideológicas que confluyeron en su seno, las estructuras de oportunidades políticas locales y los recursos movilizables. En este sentido, si bien consideramos que los aportes potenciales de los estudios locales lo serán si son puestos en diálogo con los producidos para otros espacios y escalas, dicho estudio comparativo se dejará para futuros trabajos de investigación, dado los pequeños objetivos aquí planteados.

Las organizaciones de derechos humanos no vinculadas a partidos políticos emergieron en América Latina en la década del '60. Los organismos de familiares se fueron multiplicando y obteniendo protagonismo con el correr de los años y las mujeres tuvieron una participación fundamental en los mismos, constituyéndose grupos similares a Madres de Plaza de Mayo en México, Uruguay, Paraguay, Perú, Bolivia, Brasil, Chile, El Salvador, Honduras y Guatemala. Al igual que en otras localidades de la Argentina, hemos visto que la Asociación Madres de Plaza de Mayo Filial Mar del Plata surgió en la posdictadura como un desprendimiento de la Comisión

\footnotetext{
Documentación, Registro y Archivo. Mesa Ds. Carpeta Varios. Legajo 20.228; CPM. Fondo DIPPBA. División Central de Documentación, Registro y Archivo. Mesa "De". Carpeta Entidades Varias. 541. Tomo 1.

70 A fines de los años '80, Madres de Plaza de Mayo de Santa Fe, en la línea de Hebe de Bonafini, también comenzó a señalar que la militancia de los detenidos-desaparecidos era un antecedente que no se podía ocultar. Véase Alonso, Luciano. "Variaciones en los repertorios del movimiento por los derechos humanos de Santa Fe", en Scribano, Adrián (comp.). Geometría del conflicto. Estudios de acción colectiva y conflicto social, Córdoba, Centro de Estudios Avanzados de la UNC / Universitas, 2005

${ }^{71}$ Véase Jelin, Elizabeth, "La política de la memoria...”, op. cit.; Gorini, Ulises, La otra lucha..., op. cit.

72 Véase "Madre no hay una sola". La voz de los pañuelos. Asociación Madres de Plaza de Mayo Mar del Plata, Año 2 , $\mathrm{N}^{\circ} 7$, Mar del Plata, septiembre de 2007.

${ }^{73}$ Véase Gorini, Ulises, La otra lucha..., op. cit.

${ }^{74}$ Véase Jelin, Elizabeth (comp.), Más allá de la nación: las escalas múltiples de los movimientos sociales, Editorial del Zorzal, Buenos Aires, 2003.
} 
Madres, Abuelas y Familiares de Detenidos Desaparecidos -la primera organización de derechos humanos de la ciudad surgida a raíz del accionar represivo del Estado durante la última dictadura-, a raíz de los debates que se venían desarrollando y los que surgieron en ese contexto y la diversificación de los objetivos de los integrantes de la Comisión, que se fueron alineando con distintas agrupaciones existentes del movimiento de derechos humanos. Así, en los debates suscitados en torno a las medidas del gobierno de Raúl Alfonsín, la reivindicación o no de la militancia de los desaparecidos, las consignas que debían seguir manteniéndose en la posdictadura, las exhumaciones de tumbas $\mathrm{NN}$, la conformación o no de una comisión bicameral investigadora de los crímenes cometidos, entre otros debates, un grupo de mujeres marplatenses se alineó con lo planteado por las Madres de Plaza de Mayo y formó una filial local de dicha Asociación. A su vez, los debates internos en torno a los objetivos, desafíos, búsquedas y posicionamientos, derivaron en una división de la Asociación en la cual la filial marplatense se identificó con la línea liderada por Hebe de Bonafini.

Si bien puede decirse que durante la dictadura y en la inmediata posdictadura existió una política de expansión de la Asociación liderada por Hebe de Bonafini hacia otras localidades, también puede alegarse que en varias ciudades importantes dicha organización no se conformó hasta 1985-1987, y que el proceso de surgimiento y desarrollo de la filial marplatense estuvo relacionado también con las propias características de una ciudad turística y de rango medio, que condicionaron las conductas de sus habitantes, generando alianzas, vínculos y tensiones particulares entre los integrantes del movimiento de derechos humanos local y con los integrantes de diversas organizaciones y partidos políticos. De este modo, la Asociación Madres de Plaza de Mayo de Mar del Plata tuvo un surgimiento distinto al desarrollado por la Asociación en otras ciudades como Buenos Aires o La Plata a causa también del propio contexto local, que en parte marcó los tiempos, los modos, las acciones, las estrategias, las alianzas y el impacto de dicha Asociación en el entramado político-social de la ciudad balnearia, sin por eso dejar de ser evidente que intentaron poner en circulación actividades y discursos similares a los que ya circulaban. En este sentido, coincidimos con quienes sostienen que es posible interpretar el desarrollo de los repertorios de acción del movimiento de derechos humanos en distintas localidades como una conjunción de su carácter mimético -traslado de experiencias de una localidad a otra- y su carácter adaptativo -adecuación de los repertorios de acción a las características de la localidad- $-{ }^{75}$ Esto no quiere decir que en cada localidad se reproduzcan las características generales, sino que existen tendencias, combinaciones y similitudes que deben seguir investigándose para poder obtener una explicación más compleja del proceso de formación y desarrollo del movimiento de derechos humanos.

\section{Fuentes:}

CPM. Fondo DIPPBA. División Central de Documentación, Registro y Archivo. Mesa "Ds". Carpeta Varios. Legajo 16.669; Legajo 20.228; Legajo 20.803. Tomo 1; Legajo 20.803. Tomo 2; Legajo 20.803. Tomo 4; Legajo 20.803. Tomo 5; Legajo 20.803. Tomo 6; Legajo 20.803. Tomo 7; Legajo 20.803. Tomo 8; Legajo 20.803. Tomo 9; Legajo 20.803. Tomo 10; Legajo 22.871; Legajo 22.954; 25.556; Legajo 24.700; Legajo 24.322; Legajo 25. 443; Legajo 27.542; Legajo 36.344

CPM. Fondo DIPPBA. División Central de Documentación, Registro y Archivo. Mesa "De". Carpeta Entidades Varias. 541. Tomo 1; 133

Revista Madres. La voz de los pañuelos. Asociación Madres de Plaza de Mayo de Mar del Plata. Mar del Plata. 2006-2008

\footnotetext{
75 Véase Alonso, Luciano, "Redes y dimensiones espaciales en la movilización por los derechos humanos en Argentina", Avances del Cesor, Año XII, N¹2, 2015.
} 
Informe Final de la Delegación de Mar del Plata de la Comisión Nacional sobre la Desaparición de Personas. 1984

Testimonios de integrantes del Grupo de Apoyo de Madres de Plaza de Mayo de Mar del Plata y de las integrantes de dicha Asociación. http://grupoapoyomadresmdp.blogspot.com.ar/

\section{Bibliografía:}

Aguila, Gabriela. "Las escalas de análisis en los estudios sobre el pasado reciente: a modo de introducción”. Avances del Cesor. Año XII. N¹2. 2015. pp. 91-96

Alonso, Luciano. "Redes y dimensiones espaciales en la movilización por los derechos humanos en Argentina". Avances del Cesor. Año XII. N¹2. 2015. pp. 117-139

Alonso, Luciano. "El estudio de las luchas pro derechos humanos en Argentina: problemas de enfoque en torno a la categoría de movimiento social.". En: Flier, Patricia. Dilemas, apuestas y reflexiones teórico-metodológicas para los abordajes en historia reciente. Universidad Nacional de La Plata. 2014

Alonso, Luciano. Luchas en plazas vacias de sueños. Movimiento de derechos humanos, orden local y acción antisistémica en Santa Fe. Rosario. Prohistoria. 2011

Alonso, Luciano. "Variaciones en los repertorios del movimiento por los derechos humanos de Santa Fe". En: Scribano, Adrián (comp.). Geometría del conflicto. Estudios de acción colectiva y conflicto social. Córdoba. Centro de Estudios Avanzados de la UNC / Universitas. 2005

Alonso, Luciano. "El surgimiento del movimiento argentino por los derechos humanos en perspectiva comparada". Páginas. $\mathrm{N}^{0}$ 1. Año I. La dictadura militar argentina (1976/83): investigaciones y debates. Universidad Nacional Rosario. Mayo-agosto de 2008. Disponible en línea: http://www.revistapaginas.com.ar

Alonso, Luciano. "Las luchas pro derechos humanos en Argentina: de la resistencia antidictatorial a la dispersión del movimiento social". En: Mara Burkart y Matías Giletta (coord. y ed.). Dossier Argentina: 30 años de democracia monográfico de Observatorio Latinoamericano $\mathrm{N}^{\circ} 12$, Instituto de Estudios de América Latina y el Caribe. Facultad de Ciencias Sociales. Universidad de Buenos Aires. Buenos Aires. 2013. Disponible en línea: http://iealc.sociales.uba.ar/publicaciones/observatorio-latinoamericano

Andreotti Romanin, Enrique. Memorias en conflicto. El movimiento de derechos bumanos y la construcción del Juicio por la Verdad de Mar del Plata. Mar del Plata. EUDEM. 2013

Azconegui, María Cecilia "De madres de desaparecidos a Madres de Plaza de Mayo. La definición de identidades en el seno de la Asamblea Permanente por los Derechos Humanos filial Neuquén y Alto Valle". XII Jornadas Interescuelas Departamentos de Historia. San Carlos de Bariloche. 2009

Azconegui, María Cecilia. "Derechos humanos, política y religión en Neuquén”. XIII Jornadas Interescuelas / Departamentos de Historia. Universidad Nacional de Catamarca. San Fernando del Valle de Catamarca. 2011

Bozzi, Carlos. Luna Roja. Desaparecidos de las playas marplatenses. Mar del Plata. Ediciones Suárez. 2007

Capitán, M. Belén. "Entre rezos y habeas corpus. Los orígenes de la Comisión Madres, Abuelas y Familiares de Detenidos Desaparecidos Mar del Plata". Sudamérica. N². 2013

Castro, Reynaldo. Con vida los llevaron. Memorias de madres y familiares de detenidos-desaparecidos de San Salvador de Jujuy, Argentina. Buenos Aires. La Rosa Blindada. 2004

Comisión de Memoria Portuaria. Trabajadores militantes del puerto desparecidos en Mar del Plata 19751983. Mar del Plata. Del Plata. 2011

Da Silva Catela, Ludmila No habrá flores en la tumba del pasado. La experiencia de reconstrucción del mundo de los familiares de desaparecidos. La Plata. Al Margen. 2001.

Del Pino, Ponciano y Elizabeth Jelin (Compiladores.) Luchas locales, comunidades e identidades. Madrid. Siglo XXI. 2003 
Escher, Federico. "La Asociación Madres de Plaza de Mayo durante la transición democrática en la Argentina, controversia en torno a la CONADEP". Ponencia presentada en V Jornadas de Jóvenes Investigadores. Universidad de Buenos Aires. 2009

Feld, Claudia y Marina Franco (Directoras). Democracia, bora cero. Actores, políticas y debates en los inicios de la posdictadura. Buenos Aires. Fondo de Cultura Económica. 2015

Galante, Miguel; Beatriz Luque y Marcela Fuks "Sobre terrorismo de Estado y resistencia: Los orígenes de Madres de la Plaza de Mayo". Anuario No 21 de la Escuela de Historia. Universidad Nacional de Rosario. Rosario. 2006

González Bombal, Ines. "La figura de la desaparición en la refundación del estado de derecho". En: Novarro, Marcos y Vicente Palermo (Comp.). La bistoria reciente. Argentina en democracia. Buenos Aires. EDHASA. 2004

Gorini, Ulises. La rebelión de las Madres. Historia de las Madres de Plaza de Mayo.1976-1983. Buenos Aires. Norma. 2006

Gorini, Ulises. La otra lucha. Historia de las Madres de Plaza de Mayo. 1983-1986. Buenos Aires. Norma. 2011

Jelin, Elizabeth (Compiladora). Más allá de la nación: las escalas múltiples de los movimientos sociales. Buenos Aires. Editorial del Zorzal. 2003

Jelin, Elizabeth y Pablo de Azcárate "Memoria y política: movimientos de derechos humanos y construcción democrática". América Latina Hoy. Vol. 1. Universidad de Salamanca. Salamanca. 1991

Jelin, Elizabeth "Los derechos humanos entre el Estado y la sociedad". En: Suriano, Juan (dir.) Nueva historia Argentina. Dictadura y democracia, 1976-2001. Buenos Aires. Sudamericana. 2005.

Jelin, Elizabeth "La política de la memoria: el Movimiento de Derechos Humanos y la construcción democrática en la Argentina". En: AA. VV. Juicio, castigos y memorias. Derechos bumanos y justicia en la política argentina. Buenos Aires. Nueva Visión. 1995

Kotler, Rubén (Compilador). En el país del sí me acuerdo. Los orígenes nacionales e internacionales del movimiento de derechos bumanos argentino: de la dictadura a la transición. Buenos Aires. Imago Mundi. 2014

Kotler, Rubén Los movimientos sociales: formas de resistencia a la dictadura. Madres de Detenidos Desaparecidos de Tucumán. Buenos Aires. Imago Mundi / Programa de Historia Oral de la UBA. 2006

La Capital. 100 años. 1905-2005. Mar del Plata. 25 de Mayo. 2005

Leis, Héctor Ricardo El movimiento por los derechos humanos y la política argentina. Buenos Aires. Centro Editor de América Latina. 1989

Lobato, Mirta Zaida (Directora) Mar del Plata de la prehistoria a la actualidad. Caras y contracaras de una ciudad imaginada. Facultad de Humanidades. Universidad Nacional de Mar del Plata. 1999

Lvovich, Daniel y Jorgelina Bisquert. La cambiante memoria de la dictadura militar desde 1984: Discursos públicos, movimientos sociales y legitimidad democrática. Buenos Aires. UNGS/Biblioteca Nacional. 2008

Mora, Belén. Juicios por la verdad histórica, rituales de la memoria. La reaparición de una trama en Mar del Plata. Tesis de Licenciatura. Universidad de Buenos Aires. 2005.

Morales, Virginia. "La subversión del grito. Repensando la emergencia de las Madres de Plaza de Mayo". Mora. Vol.21 N¹. Ciudad Autónoma de Buenos Aires. Junio 2015

Morales, Virginia. De la cocina a la plaza. La categoría "madre" en el discurso de las Madres de Plaza de Mayo. Villa María. EDUVIM. 2010.

Navarro, Marysa. "Lo personal es político. Las Madres de Plaza de Mayo". En: Eckstein, Susan (coord.). Poder y protesta popular. Movimientos sociales latinoamericanos. México. Siglo XXI. 2001.

Oviedo, Silvina y Carol Solís. "La génesis de los organismos de Derechos Humanos en Córdoba". La Bastilla. Revista de Historia y Politica. Vol. 1 No 0. Córdoba. Agosto de 2007 
Scocco, Marianela. "El surgimiento de los organismos de Derechos Humanos en Rosario. El caso de las filiales de Madres y Abuelas de Plaza de Mayo". XIV Jornadas Interescuelas/Departamentos de Historia. Mendoza. Octubre de 2013

Scocco, Marianela. El viento sigue soplando. Los orígenes de Madres de Plaza 25 de Mayo de Rosario (19771985). Rosario. Último Recurso. 2016

Serna, Justo y Pons, Anaclet. "Más cerca, más denso. La historia local y sus metáforas". En: Fernández, Sandra (compiladora). Más allá del territorio. La historia regionaly local como problema. Discusiones, balances y proyecciones. Rosario. Prohistoria. 2007

Sondereguer, María "Aparición con vida. El movimiento de derechos humanos en Argentina". En: Jelin, Elizabeth (ed.) Los nuevos movimientos sociales / 2. Buenos Aires. Centro Editor de América Latina. 1985 